\title{
Efficient Buchwald-Hartwig-Migita cross-coupling for DNA thioglycoconjugation
}

\author{
Nicolas Probst, ${ }^{[a]}$ Rémy Lartia, ${ }^{[b]}$ Océane Théry, ${ }^{[b]}$ Mouâd Alami, ${ }^{[a]}$ Eric Defrancq ${ }^{*[b]}$ and Samir \\ Messaoudi*[a]
}

\begin{abstract}
An efficient method for the thioglycoconjugation of iodinated oligonucleotides by Buchwald-Hartwig-Migita crosscoupling under mild conditions is reported. The method enables divergent synthesis of many different functionalized thioglycosylated ODNs in good yields, without affecting the integrity of the other $A, C$ and $\mathrm{G}$ nucleobases.
\end{abstract}

Synthetic oligonucleotides are currently investigated for various applications in medical research (e.g. control of gene expression), ${ }^{[1]}$ molecular diagnostic (e.g. DNA-based biosensors) $)^{[2]}$ as well as in biotechnology (e.g. catalysts) ${ }^{[3]}$ and nanotechnology (e.g. origami DNA for nanomaterials) $)^{[4]}$. Tremendous efforts have been made to improve the intrinsic properties of oligonucleotides by either incorporating chemical modifications in their structure (e.g phosphorothioate, 2'methoxyethoxy, locked nucleic acids...) or by covalently anchoring reporter groups with relevant properties to them. The conjugation with a reporter group is of great interest because it can be used not only to improve the existing oligonucleotide properties but also to impart it entirely new properties. ${ }^{[5]}$

In this context several approaches including the incorporation of modified phosphoramidites, step-wise (in-line) solid-phase synthesis, on-support fragment coupling, and solution-phase coupling, have been developed so far. ${ }^{[6]}$ Whereas on-support conjugation is convenient for the incorporation of a variety of reporters due to commercially available building blocks, it shows some limitations including the need for the synthesis of appropriate phosphoramidite building blocks for the introduction of non-commercially available modifications and the stability of the desired reporter during automated DNA synthesis and subsequent deprotection, the latter being carried out in drastic basic conditions. Furthermore the incorporation of bulky building block could hamper the efficiency of the phosphoramidite coupling reaction. Enzymatic incorporation of modified bases can circumvent those stability issues but polymerase-catalyzed synthesis of modified DNA could be sensitive to the incorporated reporter groups and site-selective incorporation of a single modified base is difficult to achieve..$^{[7]}$

Post-synthetic approaches can overcome these limitations and are the most extensively used for oligonucleotide conjugation. For this purpose, a number of chemical linkages have been developed by introducing a reactive moiety onto nucleic acid for subsequent coupling reaction with reporter bearing complementary reactive group. In this context, efficient

[a] Drs. N. Probst, M. Alami, S. Messaoudi BioCIS, Univ. Paris-Sud, CNRS, University Paris-Saclay, 92290, Châtenay-Malabry, France

E-mail: samir.messaoudi@u-psud.fr

[b] Dr. R. Lartia, O. Théry, Prof. E. Defrancq

University Grenoble-Alpes, DCM

CS 40700, 38058 Grenoble (France)

E-mail: eric.defrancq@univ-grenoble-alpes.fr

Supporting information for this article is given via a link at the end of the document. strategies involving oxime $e^{[8]}$ and thiol-maleimide ${ }^{[9]}$ conjugations Cu-catalyzed ${ }^{[10]}$ (or Cu-free) ${ }^{[11]}$ azide-alkyne cycloaddition, Staudinger ligation ${ }^{[12]}$ as well as Diels-Alder reactions ${ }^{[13]}$ have been reported. Another elegant method to conjugate oligonucleotides is the late stage diversification from a common halogenated oligonucleotide precursor under palladium catalysis. ${ }^{[14]}$ The first post-functionalization has been reported by Manderville who described Suzuki-Miyaura cross-coupling

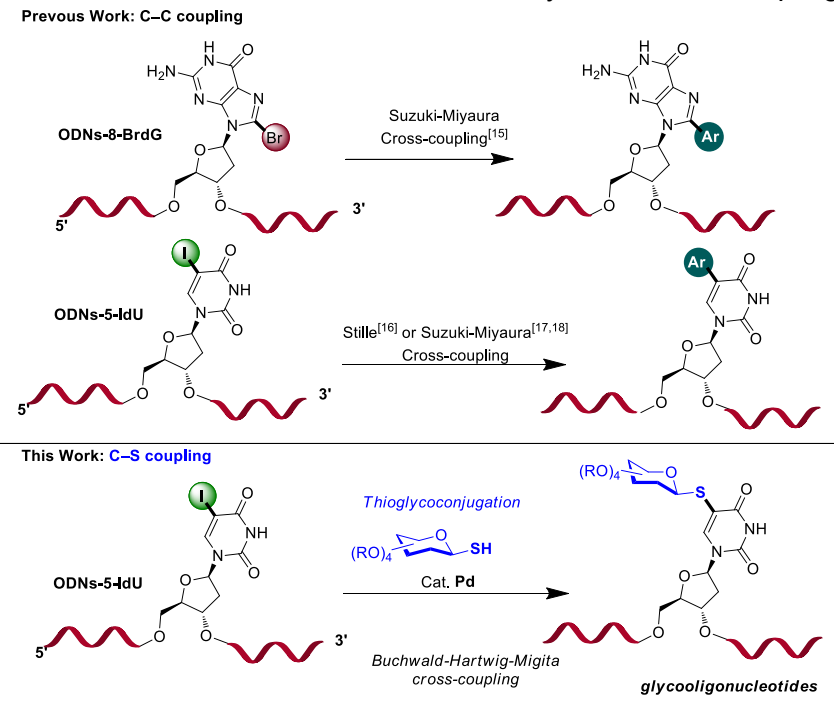

Scheme 1. Seminal examples of post functionalization of ODNs through Pdcatalyzed C-C cross-coupling reactions, $(8-\mathrm{Br}-\mathrm{dG}=8$-bromo-2'deoxyguanosine, 5-IdU = 5-iodo-2'-deoxyuridine).

reaction at $\mathrm{C}-8$ position of a guanine nucleobase from an oligonucleotide containing a single 8-bromo-2'-deoxyguanosine residue (Scheme 1). ${ }^{[15]}$ Extend to Stille coupling reaction has been next achieved by Jäschke who reported the efficient reaction of triorganotin compounds with iodine functionalized oligonucleotides and nucleotide triphosphates. ${ }^{[16]}$ Challenging substrates, like hindered boronic acids, have been incorporated by Suzuki-Miyaura cross-coupling reaction for designing photoswitchable nucleotides inside a duplex DNA. ${ }^{[17]}$ Interestingly, sensitive and useful functional groups were successfully incorporated by Davis using Suzuki-Miyaura cross-coupling reaction to 5-iodouridine under mild conditions. ${ }^{[18]}$ The highvalue of Pd-catalyzed bond formation is just beginning to reveal useful applications in biological systems as emphasized by recent results. ${ }^{[19]}$ However, to date, only C-C cross-coupling reactions (Suzuki, Stille and Sonogashira) of halogenated oligonucleotides have been reported and further development of these methodologies for the introduction of other useful groups such as sugars is of great interest. Carbohydrates are indeed involved in many biological events and play crucial roles in various cellular recognition processes. ${ }^{[20]} \mathrm{A}$ better understanding of their interactions with proteins is a major issue for the development of new therapies. Recently, Winssinger ${ }^{[21]}$ reported a dynamic cooperative glycan assembly of PNA-fucose conjugates and the biomolecular interaction between glucose and nucleobase has been demonstrated by Morales ${ }^{[22]}$ showing 
the benefits of carbohydrate incorporation on oligomeric structures. Several strategies for coupling carbohydrates to oligonucleotides are reported in the literature, ${ }^{[23]}$ and in all cases the sugar moiety is attached to the oligonucleotide through an adapted linker (platform). To the best of our knowledge there is no report concerning the direct coupling of carbohydrates on the nucleobase, that has motivated our study for the postfunctionalization of halogenated oligonucleotides with thiosugars under Pd-catalysis.

In our efforts to functionalize sugars under transition-metal catalysis, ${ }^{[24]}$ our group recently reported an efficient protocol for the palladium-catalyzed coupling of aryl and alkenyl halides with various $\alpha$ - and $\beta$-glycosyl thiols. ${ }^{[25]}$ The $C$-S bond-forming reaction was rapidly achieved (5 $\mathrm{min}$ ) at room temperature by using $\mathrm{G}_{3}$-XantPhos palladacycle pre-catalyst ${ }^{[26]}(1 \mathrm{~mol} \%)$, in the presence of $\mathrm{Et}_{3} \mathrm{~N}$ (1.0 equiv) in THF. We envisioned in the present study whether 5-iodo 2'-deoxyuridine (5-IdU) moiety could be utilized as building blocks for the synthesis of a range of thioglyco-oligonucleotides (Scheme 1). We demonstrate herein that the palladium-catalyzed thioglyconjugation is compatible with DNA and is applicable to a wide variety of oligonucleotides (i.e. with different lengths and containing purines and pyrimidines nucleobases) and carbohydrates derivatives.

To establish the appropriate conditions for the coupling reaction, tetra-O-acetylated 1-thio- $\beta$-D-glucopyranose 1a and unprotected 5 -iodouridine 2 were initially selected as coupling model substrates (for the optimization of the reaction conditions see $\mathrm{SI}$ ) A full conversion and $95 \%$ yield of isolated product $3 \mathbf{a}$ was obtained using 0.1 equiv of $\mathrm{G}_{3}$-XantPhos catalyst (Scheme 2). Importantly, the slow addition of thiosugar (for $\sim 1 \mathrm{~h}$ ) proved efficient and limited the formation of thiosugar dimer byproduct. ${ }^{[27]}$ Motivated by this result, we next explored the scope of the

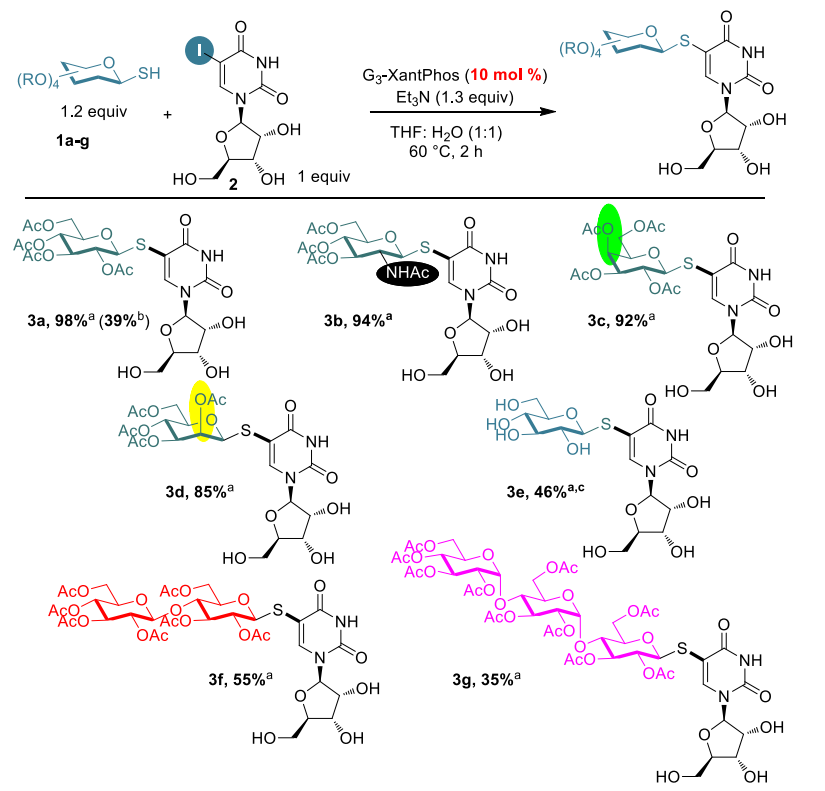

Scheme 2. Palladium-catalyzed thioglycoconjugation of 5-iodouridine 2. Reaction conditions: thiosaccharide (1.2 equiv) in THF $(0.7 \mathrm{~mL})$ added over 1 hour via a syringe pump to a solution of 5 -iodouridine $(0.07 \mathrm{mmol}, 1$ equiv), $\mathrm{G}_{3}$-XantPhos (10 mol-\%), TEA (1.3 equiv) in $\mathrm{H}_{2} \mathrm{O} / \mathrm{THF}(0.7 \mathrm{~mL} / 0.1 \mathrm{~mL})$ at $60{ }^{\circ} \mathrm{C}$. ${ }^{a}$ yield of isolated product. ${ }^{b}$ direct addition of the thiosugar. reaction by coupling on nucleoside 2 , structurally diverse $\beta$ mono-, di- and poly-thiosugar derivatives 1a-g (Scheme 2). Gratifyingly, all the coupling reactions proceeded in good yields and without epimerisation at anomeric position $\left(J_{1,2}=9 \mathrm{~Hz}\right)$. $O$ acetylated 1-thio- $\beta$-D-glucopyranose 1a, $N$-Ac-1-thio- $\beta$-Dglucopyranose 1b, 1-thio- $\beta$-D-galactopyranose $1 \mathrm{c}$ and 1-thio- $\beta$ D-mannopyranose $\mathbf{1 d}$ were efficiently coupled with 2 to give corresponding thioglycoconjugates $\mathbf{3 a - d}$. Moreover, the reaction is not limited to monosaccharides, but can be applied to more complex di- and trisaccharide derivatives. Thus, O-acetylated $1-$ thio- $\beta$-D-cellobiose $\mathbf{1 f}$ and 1-thio- $\beta$-D-maltotriose $\mathbf{1 g}$ were reacted with 5-iodouridine $\mathbf{2}$ to give corresponding glycoconjugates $\mathbf{3 f}$ and $\mathbf{3 g}$ in $55 \%$ and $35 \%$ yield, respectively. It is noteworthy that fully deprotected sugars can be also used: as an example, the reaction of 2 with 1-thio- $\beta$-D-glucose afforded product $3 e$ in satisfactory $46 \%$ yield.

These results with nucleoside 2 prompted us to explore the coupling of iodine containing oligonucleotides with various thiosugars. 5-iodo-2'-deoxyuridine modification was incorporated into oligonucleotides by using the commercially available C5iodo-dU phosphoramidite and the final deprotection of the nucleobases was achieved in $28 \%$ ammonia at room temperature for $24 \mathrm{~h}$ as recommended (see SI for HPLC profiles and ESMS analysis of iodine containing oligonucleotides). 7-mer ODN $\mathbf{T}_{3} \mathbf{X T}_{4}$ (in which $\mathrm{X}$ represents 5-iodo-2'-deoxyuridine moiety) and 1-hexanethiol were first chose as model substrates to identify the best conditions for the coupling reaction (Table 1). The reactions were monitored by RP-HPLC and the rate of conversion was estimated from HPLC analysis.

Table 1. Optimization of the coupling reaction of $\mathbf{T}_{3}-\mathbf{X}-\mathbf{T}_{4}$ with 1-hexanethiol. ${ }^{[\mathrm{a}]}$
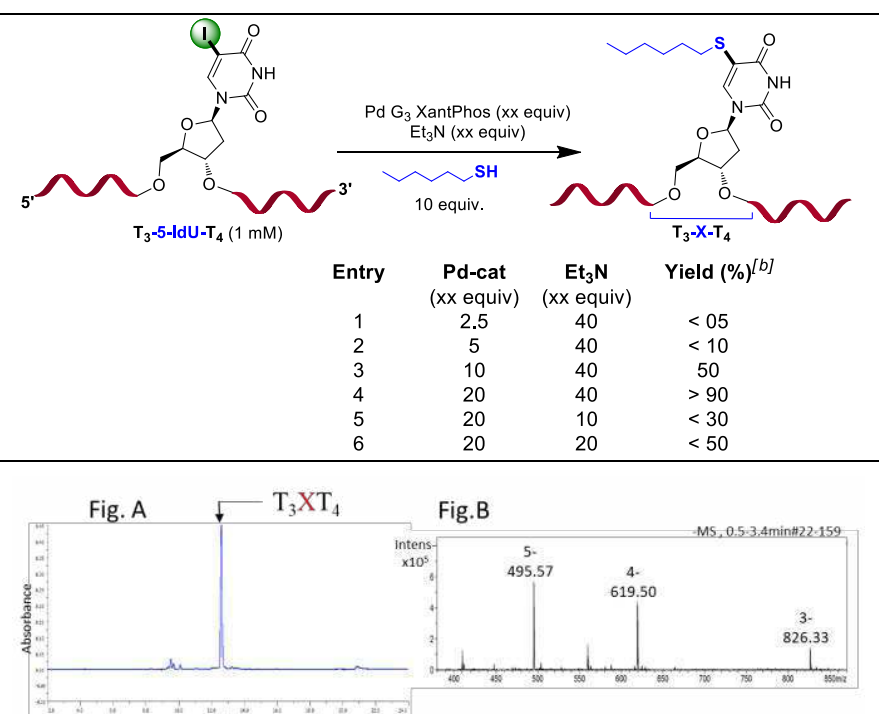

(Fig. A) RP-HPLC chromatogram of crude reaction mixture of $\mathrm{T}_{3} \mathrm{XT}_{4}$ with 1hexanethiol of entry 4. (Fig. B) ESI mass spectrum of $\mathrm{T}_{3} \mathrm{XT}_{4}$

[a] See the supporting information for the experimental procedure. ${ }^{[b]}$ The rate of conversion was estimated from HPLC profile by comparison of the surface of the peak corresponding to the oligonucleotide conjugate with the surfaces of the other minor peaks.

It was found that the quantity of G3-XantPhos reagent is crucial as the addition of almost 20 equivalents was required to obtain 
the complete conversion of the starting material (Table 1, entry 4. See also RP-HPLC on Figure A, ESI mass in B and SI: Figure S23 for HPLC profiles). Likewise the quantity of triethylamine must be adjusted to 40 equivalents: addition of less quantity led to incomplete conversion of the starting oligonucleotide (Table 1, entry 4-6, Figure S24 for HPLC profiles). The effect of the temperature was also investigated and revealed a slightly impact on the coupling reaction (data not shown): nevertheless the temperature was kept at $60^{\circ} \mathrm{C}$ as the room temperature reactions showed some by-products formation. Finally the quantity of 1-hexanethiol must be maintained at almost 10 equivalents. These optimized conditions were applied for

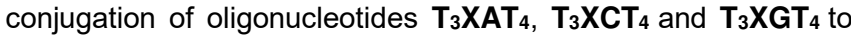
consider the stability of $A, C$ and $G$ nucleobases during the coupling reaction (Scheme 3 ). The iodine containing oligonucleotides $\mathbf{T}_{3} \mathbf{X A T _ { 4 }}, \mathbf{T}_{3} \mathbf{X C T _ { 4 }}$ and $\mathbf{T}_{3} \mathbf{X G T}_{4}$ were efficiently converted to the corresponding conjugates thus demonstrating that $P d$ catalyst do not affect the integrity of $A, C$ and $G$ nucleobases (Figures S35-S37 for HPLC profiles). The coupling reaction was then performed with hetero-oligonucleotides TTAGGACAXGCT and GCTXCCACA as well as with the longer $\mathrm{T}_{10} \mathrm{XT} \mathrm{T}_{9}$ oligonucleotide and revealed to be very efficient to afford the corresponding conjugates (Figures S38, S39 and S34, respectively for HPLC profiles). The reaction was also achieved for the incorporation of two reporter moieties by using bismodified oligonucleotide $\mathbf{T}_{3} \mathbf{X T}_{3} \mathbf{X} \mathbf{T}_{3}$. Again, the conversion to the corresponding conjugate was very efficient to afford the bisconjugate (Figure S40 for HPLC profile). All the conjugation products with 1-hexanethiol were purified by reverse-phase HPLC and then characterized by ESMS analysis (Table S2 and Figures S63-S70).

The optimized conditions were then applied for the conjugation of various oligonucleotides sequences with $O$-acetylated thiocarbohydrates derivatives $\mathbf{1 a - g}$ (Scheme 3). The reactions were monitored by RP-HPLC. For all the conjugation reactions, the HPLC profiles of the crude mixtures showed the disappearance of the starting material with the formation of the corresponding thioglyco-oligonucleotide as the major product (Scheme 3B as an example and Figures S41-S54). The rate of conversion for all the conjugation reactions was estimated by HPLC analysis to be superior to $90 \%$ except for bis-conjugation of $\mathbf{T}_{3} \mathbf{X T}_{3} \mathbf{X T}_{3} \quad(73 \%)$. Then thoroughly purifications including EDTA treatment and centrifugation to separate the palladium containing solid followed by size-exclusion chromatography and next RP-HPLC were performed to remove the traces of Pd (see supporting information page 34). The different corresponding carbohydrate oligonucleotide conjugates were obtained in nearly $80 \%$ isolated yields. They were characterized by means of ESMS mass spectrometry analysis that showed a good agreement between the experimentally determined molecular weights and the calculated values (Table S2 and Figures S71S84). ${ }^{[29]}$ It is noteworthy that the use of unprotected thio-sugars for the coupling reaction was discarded because of purification problems: indeed the RP-HPLC analyses showed quite similar retention times for both starting materials and conjugates.

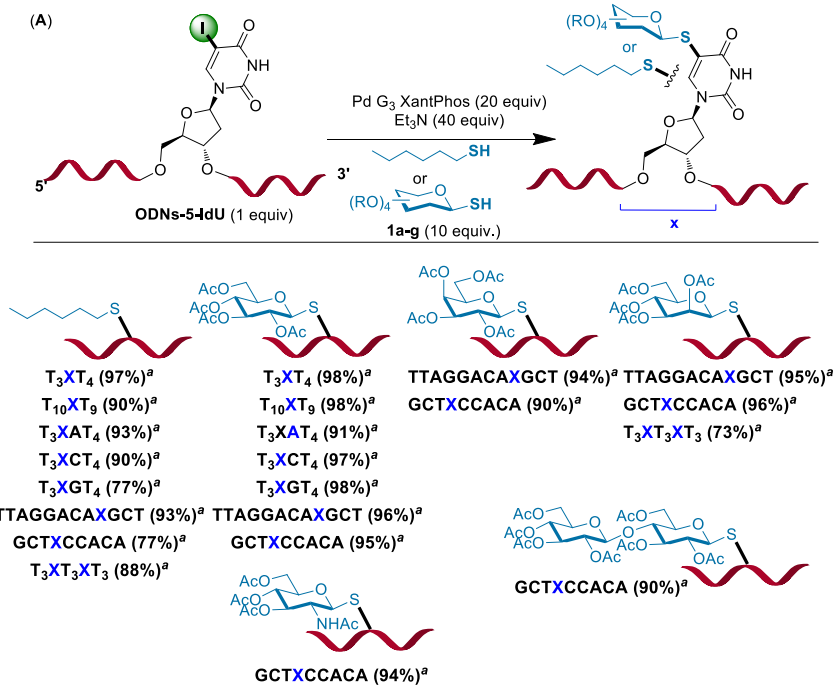

(B)Example of HPLC profile for the coupling reaction: $\mathrm{T}_{3} \mathrm{XT}_{4}$ with Glu(OAC)$)_{4}-\mathrm{SH} 1 \mathrm{a}$

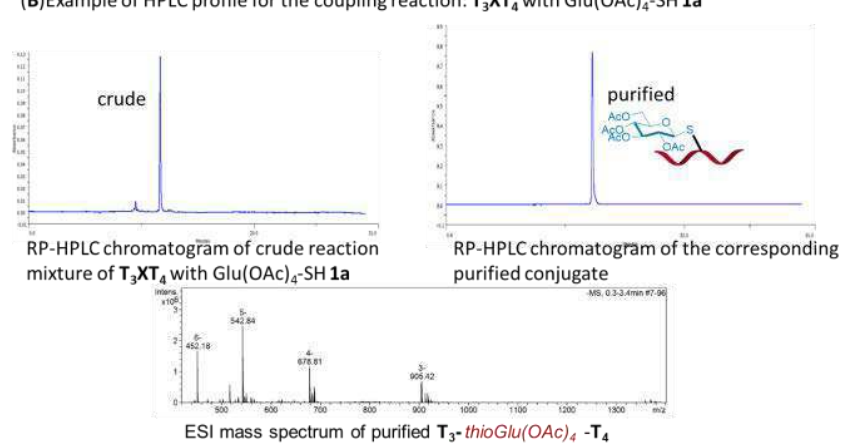

Scheme 3. A/ Palladium-catalyzed thioglycoconjugation of 5-iodo-2' deoxyuridine containing oligonucleotides. Reaction conditions: thiol derivatives $(400 \mathrm{nmol})$ in THF is added to a solution of oligonucleotide $(40 \mathrm{nmol})$, G3Xantphos $\mathrm{Pd}(800 \mathrm{nmol})$, TEA $(1600 \mathrm{nmol})$ in $\mathrm{H}_{2} \mathrm{O} / \mathrm{THF}(7 / 1, \mathrm{v} / \mathrm{v})$ and heated at $60{ }^{\circ} \mathrm{C}$ for $20 \mathrm{~min}$. ${ }^{\text {[a] }}$ Rate of conversion estimated from HPLC. B/ Example of HPLC profile for the coupling reaction: RP-HPLC chromatogram of crude reaction mixture (on left) of $\mathbf{T}_{3} \mathbf{X T}_{4}$ with $\mathrm{Glu}(\mathrm{OAc})_{4}-\mathrm{SH}$ 1a and corresponding purified conjugate (on right).

In conclusion, we have demonstrated that the palladacycle precatalyst G3-XantPhos displays a high activity for thioglycoconjugation of an array of oligonucleotides. The mild reaction conditions allow direct access to a range of glycoconjugates that are otherwise not easily accessible. We expect this simple and general protocol to be of broad utility for the synthesis and development of new oligoglycoconjugates of interest. In particular, efforts are in progress to incorporate up to four carbohydrate moieties through this strategy to diverse structural DNA architectures such as G-quadruplex or i-motif and to study the recognition of those biomolecular systems with lectins.

\section{Acknowledgements}

Authors gratefully acknowledge CNRS, University Paris-Sud, University Grenoble Alpes, "Agence Nationale de la Recherche" (ANR-15-CE29- 0002 and ANR-16-CE11-0006-01) and la Ligue Contre le Cancer through an Equipe Labellisée 2014 for financial support. Biocis laboratory is a member of the 
Laboratory of Excellence LERMIT supported by a grant (ANR10-LABX-33). The NanoBio-ICMG platforms (FR 2607) and Labex ARCANE (ANR-11-LABX-0003-01) are also acknowledged for their support.

Keywords: Oligonucleotides, thioglycoconjugation, Pd-catalysis, thiosaccharide, DNA-glycoconjugates.

[1] (a) T. Robak, Clin. Cancer Drugs 2014, 1, 2-10; (b) L. P. Jordheim, D. Durantel, F. Zoulim, C. Dumontet, Nat. Rev. Drug Discov. 2013, 12 447-464; (c) E. De Clercq, Nucleosides, Nucleotides and Nucleic Acids 2009, 28, 586-600; (d) M. J. Sofia, W. Chang, P. A. Furman, R. T. Mosley, B. S. Ross, J. Med. Chem. 2012, 55, 2481-2531; (e) Q. Dai, D. Xu, K. Lim, R. G. Harvey, J. Org. Chem. 2007, 72, 4856-4863; (f) E. Champeil, P. Pradhan, M. K. Lakshman, J. Org. Chem. 2007, 72 5035-5045; (g) M. K. Lakshman, P. Gunda, Org. Lett. 2003, 5, 39-42. (h) A. Matarazzo, R. H. E. Hudson, Tetrahedron 2015, 71, 1627-1657 (i) A. A. Tanpure, M. G. Pawar, S. G. Srivatsan, Isr. J. Chem. 2013, 53, 366-378.

[2] (a) S. L. Beaucage, Curr. Med. Chem. 2001, 8, 1213-1244; (b) I. Willner, M. Zayats, Angew. Chem. Int. Ed. 2007, 46, 6408-6418; (c) J. Liu, Z. Cao, Y. Lu, Functional Nucleic Acid Sensors, 2009, 109, 1948-1998.

[3] (a) S. Park, H. Sugiyama, Angew. Chem. Int. Ed. 2010, 49, 3870-3878 (b) Z. Tang, D. P. N. Gonçalves, M. Wieland, A. Marx, J. S. Hartig ChemBioChem 2008, 9, 1061-1064; (c) S. K. Silverman, Angew. Chem. Int. Ed. 2010, 49, 7180-7201; (d) L.-X. Wang, J.-F. Xiang, Y.-L. Tanga Adv. Synth. Catal. 2015, 357, 13-20; (d) N. Duchemin, I. HeathApostolopoulos, M. Smietana, S. Arseniyadis, Org. Biomol. Chem. 2017, 15, 7072-7087; (e) S. K. Silverman, Acc. Chem. Res. 2009, 42, 1521-1531.

[4] (a) W. Su, V. Bonnard, G. A. Burley, Chem. Eur. J. 2011, 17, 7982 7991; (b) M. Famulok, J. S. Hartig, G. Mayer, Chem. Rev. 2007, 107, 3715-3743; (c) F. A. Aldaye, A. L. Palmer, H. F. Sleiman, Science 2008, 321, 1795-1799.

[5] (a) R. L. Juliano, X. Ming, O. Nakagawa, Acc. Chem. Res. 2012, 45, 1067-1076; (b) M. R. Alam, X. Ming, O. Nakagawa, J. Jin, R. L. Juliano Bioorg. Med. Chem. 2013, 21, 6217-6223.

[6] (a) Y. Singh, P. Murat, E. Defrancq, Chem. Soc. Rev. 2010, 39, $2054-$ 2070; (b) H. Lönnberg, Beilstein J. Org. Chem. 2017, 13, 1368-1387.

[7] (a) "Polymerase Synthesis of Base-Modified DNA", J. Dadová, H. Cahová, M. Hocek, in Modified Nucleic Acids, Nucleic Acids and Molecular Biology Series (Eds.: K. Nakatani, Y. Tor), Springer, 2016, 31 pp. 123-144; (b) J. Matyašovský, P. Perlíková, V. Malnuit, R. Pohl, M. Hocek, Angew. Chem. Int. Ed. 2016, 55, 15856-15859; (c) P. Ménova H. Cahova, M. Plucnara, L. Havran, M. Fojta, M. Hocek, Chem. Commun. 2013, 49, 4652-4654; (d) S. Jäger, G. Rasched, H Kornreich-Leshem, M. Engeser, O. Thum, M. Famulok, J. Am. Chem. Soc. 2005, 127, 15071-15082.

[8] (a) A. Meyer, N. Spinelli, P. Dumy, J.-J. Vasseur, F. Morvan, E. Defrancq, J. Org. Chem. 2010, 75, 3927-3930; (b) M. Villien, S. Deroo, E. Gicquel, E. Defrancq, C. Moucheron, A. K. De Mesmaeker, P. Dumy, Tetrahedron 2007, 63, 11299-11306; (c) N. Spinelli, O. P. Edupuganti, E. Defrancq, P. Dumy, Org. Lett. 2007, 9, 219-222; (d) O. P. Edupuganti, Y. Singh, E. Defrancq, P. Dumy, Chem. Eur. J. 2004, 10, 5988-5995; (e) T. S. Zatsepin, D. A. Stetsenko, A. A. Arzumanov, E. A. Romanova, M. J. Gait, T. S. Oretskaya, Bioconjugate Chem. 2002, 13, 822-830.

[9] (a) H. Eberhard, F. Diezmann, O. Seitz, Angew. Chem. Int. Ed. 2011, 50, 4146-4150; Angew. Chem. 2011, 123, 4232-4236; (b) A. Sánchez, E. Pedroso, A. Grandas, Org. Biomol. Chem. 2012, 10, 8478-8483; (c) S. Hara, T. Nojima, K. Seio, M. Yoshida, T. Hisabori, Biochim Biophys Acta 2013, 1830, 3077-3081.

[10] (a) A. H. El-Sagheer, T. Brown, Chem. Soc. Rev. 2010, 39, 1388-1405; (b) E. Paredes, S. R. Das, ChemBioChem 2011, 12, 125-131.
[11] (a) K. Gutsmiedl, D. Fazio, T. Carell, Chem. Eur. J. 2010, 16, 68776883; (b) A. M. Jawalekar, S. Malik, J. M. M. Verkade, B. Gibson, N. S Barta, J. C. Hodges, A. Rowan, F. L. vanDelft, Molecules 2013, 18, 7346-7363; (c) M. Merkel, K. Peewasan, S. Arndt, D. Ploschik, H.-A Wagenknecht, ChemBioChem 2015, 16, 1541-1553.

[12] (a) "Covalent Organic Functionalization of Nucleic Acids", M. Arthur, M. Etheve-Quelquejeu in Chemistry of Organo-Hybrids: Synthesis and Characterization of Functional Nano-Objects (Eds.: B. Charleux, C Copéret, E. Lacôte), Wiley, Hoboken, 2015, pp. 272-298; (b) S. H. Weisbrod, A. Baccaro, A. Marx, Methods Mol. Biol. 2011, 751, 195-207.

[13] (a) J. Schoch, M. Wiessler, A. Jäschke, J. Am. Chem. Soc. 2010, 132 8846-8847; (b) A. H. El-Sagheer, V. V. Cheong, T. Brown, Org. Biomol. Chem. 2011, 9, 232-235; (c) H. Bußkamp, E. Batroff, A. Niederwieser, O. S. Abdel-Rahman, R. F. Winter, V. Wittmann, A. Marx, Chem. Commun. 2014, 50, 10827-10829; (d) J. Schoch, M. Staudt, A. Samanta, M. Wiessler, A. Jäschke, Bioconjugate Chem. 2012, 23 , 1382-1386.

[14] E. Defrancq, S. Messaoudi, ChemBioChem, 2017, 18, 426-431.

[15] A. Omumi, D. G. Beach, M. Baker, W. Gabryelski, R. A. Manderville, J. Am. Chem. Soc. 2011, 133, 42-50.

[16] A. Krause, A. Hertl, F. Muttach, A. Jäschke, Chem. Eur. J. 2014, 20, 16613-16619

[17] H. Cahová, A. Jäschke, Angew. Chemie Int. Ed. 2013, 52, 3186-3190.

[18] L. Lercher, J. F. McGouran, B. M. Kessler, C. J. Schofield, B. G. Davis, Angew. Chemie Int. Ed. 2013, 52, 10553-10558.

[19] (a) E. V. Vinogradova, C. Zhang, A. M. Spokoyny, B. L. Pentelute, S. L. Buchwald, Nature, 2015, 526, 687-691; (b) J. Willwacher, R. Raj, S. Mohammed, B. G. Davis, J. Am. Chem. Soc. 2016, 138, 8678-8681. (c) R. A. A. Al-Shuaeeb, S. Kolodych, O. Koniev, S. Delacroix, S. Erb, S Nicolaÿ, J.-C. Cintrat, J.-D. Brion, S. Cianférani, M. Alami, A. Wagner, S. Messaoudi, Chem. Eur. J., 2016, 22, 11365-11370.

[20] (a) C. R. Bertozzi, L. L. Kiessling, Science, 2001, 291, 2357-2364; (b) H. C. Hang, C. R. Bertozzi, Bioorg. Med. Chem. 2005, 13, 5021-5034.

[21] T. Machida, A. Novoa, É. Gillon, S. Zheng, J. Claudinon, T. Eierhoff, A Imberty, W. Römer, N. Winssinger, Angew. Chemie Int. Ed. 2017, 56 6762-6766.

[22] E. Vengut-Climent, I. Gómez-Pinto, R. Lucas, P. Peçalver, A. Aviçó, C. F. Guerra, F. M. Bickelhaupt, R. Eritja, C. Gonzulez, J. C. Morales, Angew. Chemie Int. Ed. 2016, 55, 8643-8647.

[23] (a) N. Spinelli, E. Defrancq, F. Morvan, Chem. Soc. Rev., 2013, 42, 4557-4573; (b) G. Pourceau, A. Meyer, J.-J. Vasseur, F. Morvan, J. Org. Chem., 2009, 74, 1218-1222; (c) K. Matsuura, M. Hibino, Y. Yamada, K. Kobayashi, J. Am. Chem. Soc. 2001, 123, 357-358; (d) M. Dubber, J. M. J. Frechet, Bioconjugate Chem. 2003, 14, 239-246, (e) J. Katajisto, P. Heinonen, H. Lonnberg, J. Org. Chem. 2004, 69, 7609-7615; (f) J. Katajisto, P. Virta, H. Lonnberg, Bioconjugate Chem. 2004, 15, 890896; (g) J. D'Onofrio, J. M. de Champdore, L. De Napoli, D. Montesarchio, G. Di Fabio, Bioconjugate Chem. 2005, 16, 1299-1309; (h) Y. Singh, O. Renaudet, E. Defrancq, P. Dumy, Org. Lett. 2005, 7, 1359-1362; (i) D. Forget, O. Renaudet, E. Defrancq, P. Dumy, Tet. Lett. 2001, 42, 7829-7832; (j) C. Scheibe, A. Bujotzek, J. Dernedde, M. Weber, O. Seitz, Chem. Sci., 2011, 2, 770-775.

[24] (a) A. Bruneau, M. Roche, A. Hamze, J.-D Brion, M. Alami, S Messaoudi, Chem. Eur. J. 2015, 21, 8375-8379; (b) A. Chabrier, A. Bruneau, S. Benmahdjoub, B. Benme-rad, S. Belaid, J. D Brion, M. Alami, S. Messaoudi, Chem. Eur. J., 2016, 22, 15006-15010; (c) T. H. Luong, J.-D. Brion, E. Lescop, M. Alami, S. Messaoudi, Org. Lett. 2016, 18, 2126-2129; (d) N. Probst, G. Grelier, N. Ghermani, V. Gandon, M Alami, S. Messaoudi, Org. Lett. 2017, 19, 5038-5041.

[25] A. Bruneau, M. Roche, A. Hamze, J.-D. Brion, M. Alami, S. Messaoudi, Chem. Eur. J., 2015, 21, 8375-8379.

[26] A. Bruneau, M. Roche, M. Alami, S. Messaoudi, ACS Catalysis 2015, 5 , 1386-1396.

[27] Copper-mediated arylsulfanylations of pyrimidine nucleosides and nucleotides have been recently reported (ref [28]). We tried this strategy and unfortunately under those conditions, the coupling of 5- 
iodouridine 2 with tetra-O-acetylated 1-thio- $\beta$-D-glucopyranose 1a failed.

[28] F. Botha, M. Slavíčková, R. Pohl, M. Hocek, Org. Biomol. Chem., 2016 14, 10018-10022.

[29] No trace of residual amounts of $\mathrm{Pd}$ could be detected by mass spectrometry analysis. 